\title{
Stereotactic radiosurgery for vestibular schwannomas: average 10-year follow-up results focusing on long-term hearing preservation
}

\author{
Shinya Watanabe, MD, PhD, ${ }^{1,2}$ Masaaki Yamamoto, MD, PhD, ${ }^{1,3}$ Takuya Kawabe, MD, PhD, ${ }^{4}$ \\ Takao Koiso, MD, ${ }^{1,5}$ Tetsuya Yamamoto, MD, PhD, ${ }^{5}$ Akira Matsumura, MD, PhD, ${ }^{5}$ and \\ Hidetoshi Kasuya, MD, PhD ${ }^{3}$
}

${ }^{1}$ Katsuta Hospital Mito GammaHouse, Hitachi-naka; ${ }^{2}$ Department of Neurosurgery, Mito Medical Center, Ibaraki-machi;
${ }^{3}$ Department of Neurosurgery, Tokyo Women's Medical University Medical Center East, Tokyo; ${ }^{4 D e p a r t m e n t ~ o f ~ N e u r o s u r g e r y, ~}$
Kyoto Prefectural University of Medicine Graduate School of Medical Sciences, Kyoto; and ${ }^{5}$ Department of Neurosurgery,
Faculty of Medicine, University of Tsukuba, Japan

OBJECTIVE The aim of this study was to reappraise long-term treatment outcomes of stereotactic radiosurgery (SRS) for vestibular schwannomas (VSs). The authors used a database that included patients who underwent SRS with a unique dose-planning technique, i.e., partial tumor coverage designed to avoid excess irradiation of the facial and cochlear nerves, focusing on tumor control and hearing preservation. Clinical factors associated with post-SRS tumor control and long-term hearing preservation were also analyzed.

METHODS This institutional review board-approved, retrospective cohort study used the authors' prospectively accumulated database. Among 207 patients who underwent Gamma Knife SRS for VSs between 1990 and 2005, 183 (who were followed up for at least 36 post-SRS months) were studied. The median tumor volume was $2.0 \mathrm{~cm}^{3}$ (range $0.05-26.2 \mathrm{~cm}^{3}$ ). The median prescribed dose at the tumor periphery was $12.0 \mathrm{~Gy}$ (range 8.8-15.0 Gy; $12.0 \mathrm{~Gy}$ was used in 171 patients [93\%]), whereas tumor portions facing the facial and cochlear nerves were irradiated with $10.0 \mathrm{~Gy}$. As a result, $72 \%-99 \%$ of each tumor was irradiated with the prescribed dose. The mean cochlear doses ranged from 2.3 to $5.7 \mathrm{~Gy}$ (median $4.1 \mathrm{~Gy}$ ).

RESULTS The median durations of imaging and audiometric follow-up were 114 months (interquartile range 73-144 months) and 59 months (interquartile range 33-109 months), respectively. Tumor shrinkage was documented in 110 $(61 \%)$, no change in $48(27 \%)$, and enlargement in the other $22(12 \%)$ patients. A further procedure (FP) was required in $15(8 \%)$ patients. Thus, the tumor growth control rate was $88 \%$ and the clinical control rate (i.e., no need for an FP) was $92 \%$. The cumulative FP-free rates were $96 \%, 93 \%$, and $87 \%$ at the 60 th, 120 th, and 180 th post-SRS month, respectively. Six (3\%) patients experienced facial pain, and 2 developed transient facial palsy. Serviceable hearing was defined as a pure tone audiogram result better than $50 \mathrm{~dB}$. Among the 66 patients with serviceable hearing before SRS who were followed up, hearing acuity was preserved in $23(35 \%)$. Actuarial serviceable hearing preservation rates were $49 \%, 24 \%$, and $12 \%$ at the 60 th, 120 th, and 180 th post-SRS month, respectively. On univariable analysis, only cystic-type tumor (HR 3.36, 95\% Cl 1.18-9.36; $p=0.02$ ) was shown to have a significantly unfavorable association with FP. Multivariable analysis followed by univariable analysis revealed that higher age ( $\geq 65$ years: $\mathrm{HR} 2.66,95 \% \mathrm{Cl} 1.16-5.92 ; p=0.02)$, larger tumor volume $\left(\geq 8 \mathrm{~cm}^{3}: \mathrm{HR} 5.36,95 \% \mathrm{Cl} 1.20-17.4 ; p=0.03\right.$ ), and higher cochlear dose (mean cochlear dose > 4.2 Gy: HR 2.22, $95 \% \mathrm{Cl} 1.07-4.77 ; p=0.03$ ) were unfavorable factors for hearing preservation.

CONCLUSIONS Stereotactic radiosurgery achieved good long-term results in this series. Tumor control was acceptable, and there were few serious complications in patients with small- to medium-sized VSs. Unfortunately, hearing preservation was not satisfactory. However, the longer the observation period, the more important it becomes to compare post-SRS hearing decreases with the natural decline in untreated cases.

http://thejns.org/doi/abs/10.3171/2016.7.GKS161494

KEY WORDS stereotactic radiosurgery; vestibular schwannoma; Gamma Knife; long-term; cochlea; hearing preservation

ABBREVIATIONS FP = further procedure; IQR = interquartile range; $\mathrm{PTA}=$ pure tone audiography; $\mathrm{SDS}$ = speech discrimination scores; SRS = stereotactic radiosurgery; VS = vestibular schwannoma.

SUBMITTED June 8, 2016. ACCEPTED July 5, 2016.

INCLUDE WHEN CITING DOI: 10.3171/2016.7.GKS161494. 
$\mathrm{M}$ ANAGEMENT options for patients with vestibular schwannoma (VS) include observation, microsurgical resection, stereotactic radiosurgery (SRS) alone, and palliative surgery followed by SRS. Although debate continues as to which therapeutic option is optimal for small- to medium-sized VSs,$^{30}$ SRS is generally regarded as either a primary or a postoperative procedure for VSs with a diameter smaller than $3.0 \mathrm{~cm} .{ }^{14} \mathrm{Ac}-$ cording to a database of the International Leksell Gamma Knife Society, as of the end of 2014, the number of patients with VS who have been treated with Gamma Knife SRS worldwide since 1991 exceeded 85,000. Although considerable numbers of retrospective studies have been published, accumulated knowledge as to post-SRS longterm results is not yet considered sufficient. In particular, post-SRS long-term hearing preservation is a problem that still requires discussion, as emphasized by Carlson et al. ${ }^{4}$

Our aim was to reappraise long-term treatment outcomes of SRS for VSs using our database, which includes patients who underwent SRS with our unique dose-planning technique, i.e., partial tumor coverage designed to avoid excess irradiation of the facial and cochlear nerves, focusing on tumor control and hearing preservation. We also analyzed clinical factors associated with post-SRS tumor control and long-term hearing preservation.

\section{Methods}

\section{Study Design and Patient Selection}

This institutional review board-approved, retrospective cohort study used our prospectively accumulated database, including 207 patients who underwent Gamma Knife SRS for VSs between 1990 and 2005. Among the 207 patients, 14 were treated at Tokyo Women's Medical University before June 1998; thereafter, 193 were treated at the Katsuta Hospital Mito GammaHouse. One coauthor (M.Y.) performed every SRS procedure in all 207 patients.

Among the 207 patients, we studied $183(88 \%)$ in whom long-term outcomes (at least 36 post-SRS months) were available. Twenty-four patients were excluded; 20 of them were lost to follow-up before 36 months and 4 died due to unrelated diseases before the 36th post-SRS month. Characteristics of the 183 patients are summarized in Table 1. The median age was 56 years (range $11-80$ years). The median tumor volume was $2.0 \mathrm{~cm}^{3}$ (range $0.05-26.2 \mathrm{~cm}^{3}$ ). Cystic-type tumor, defined as the cyst accounting for more than $60 \%$ of the total tumor volume, was observed in 39 (21\%) patients. The Koos classification was used to evaluate tumor extension. Facial and cochlear nerve functions were graded using House-Brackmann grading ${ }^{11}$ and pure tone audiography (PTA), respectively. Among the 183 patients, $47(26 \%)$ already had facial nerve disturbances prior to SRS. Of these 47 patients, 29 were classified as having House-Brackmann Grade II function and 17 of the other 18 as having Grades III-V function. The latter 17 patients had previously undergone surgery. Before SRS, 74 patients (41\%) patients had serviceable hearing on the tumor side.

\section{Radiosurgical Technique}

Before SRS, the treatment strategy was explained in detail to each patient, and at least 1 adult relative (by M.Y.).
TABLE 1. Baseline characteristics of 183 patients

\begin{tabular}{|c|c|}
\hline Characteristic & Value* $^{*}$ \\
\hline \multicolumn{2}{|l|}{ Sex } \\
\hline M & $83(45)$ \\
\hline $\mathrm{F}$ & $100(55)$ \\
\hline Age in yrs, median (range) & $56(11-80)$ \\
\hline Neurofibromatosis Type II & $10(5)$ \\
\hline Hx of sudden deafness & $14(8)$ \\
\hline \multicolumn{2}{|l|}{ Side } \\
\hline $\mathrm{Rt}$ & $98(54)$ \\
\hline Lt & $85(46)$ \\
\hline \multicolumn{2}{|l|}{ Prior surgical intervention } \\
\hline Tumor removal & $56(31)$ \\
\hline VP shunt & $6(3)$ \\
\hline Pre-SRS growth & $57(31)$ \\
\hline \multicolumn{2}{|l|}{ Tumor characteristic } \\
\hline Cystic† & $39(21)$ \\
\hline Solid & $144(79)$ \\
\hline Tumor vol in $\mathrm{cm}^{3}$, median (range) & $2.00(0.05-26.2)$ \\
\hline \multicolumn{2}{|l|}{ Koos classification, stage } \\
\hline 1 & $20(11)$ \\
\hline II & $73(40)$ \\
\hline III & $56(31)$ \\
\hline IV & $34(19)$ \\
\hline Trigeminal neuropathy & $6(5)$ \\
\hline \multicolumn{2}{|l|}{ House-Brackmann grade } \\
\hline I & $136(74)$ \\
\hline II & $29(16)$ \\
\hline III & $10(5)$ \\
\hline IV & $4(2)$ \\
\hline V & $4(2)$ \\
\hline \multicolumn{2}{|l|}{ Gardner-Robertson scale, $\mathrm{dB} \ddagger$} \\
\hline$\leq 30$ & $40(22)$ \\
\hline$>30 \& \leq 50$ & $34(19)$ \\
\hline$>50$ & $109(59)$ \\
\hline
\end{tabular}

$\mathrm{Hx}=$ history; $\mathrm{VP}=$ ventriculoperitoneal.

* All values are expressed as no. of patients (\%) unless otherwise specified.

$\dagger$ Volume of cyst(s) exceeded $60 \%$ of the entire tumor volume.

‡ Scale described in Gardner and Robertson. ${ }^{6}$

Written informed consent was obtained from all patients. Radiosurgery was performed using a Gamma Unit model B (Elekta Instrument AB). Between 1988 and June 2003, SRS was performed using a Leksell GK model B unit (Elekta); thereafter, a Leksell GK model C unit (Elekta) was used. A Leksell model G stereotactic coordinate frame (Elekta Instrument $\mathrm{AB}$ ) was applied while patients were under local anesthesia. For target coordinate determination and dose planning, stereotactic gadolinium-enhanced T1-weighted axial MR images with a slice thickness of 1 or $2 \mathrm{~mm}$, depending on tumor size, were obtained. Also, 3D constructive interference in steady state axial MR images and CT axial images without contrast enhancement were routinely used to identify cranial nerves and bone structures. 


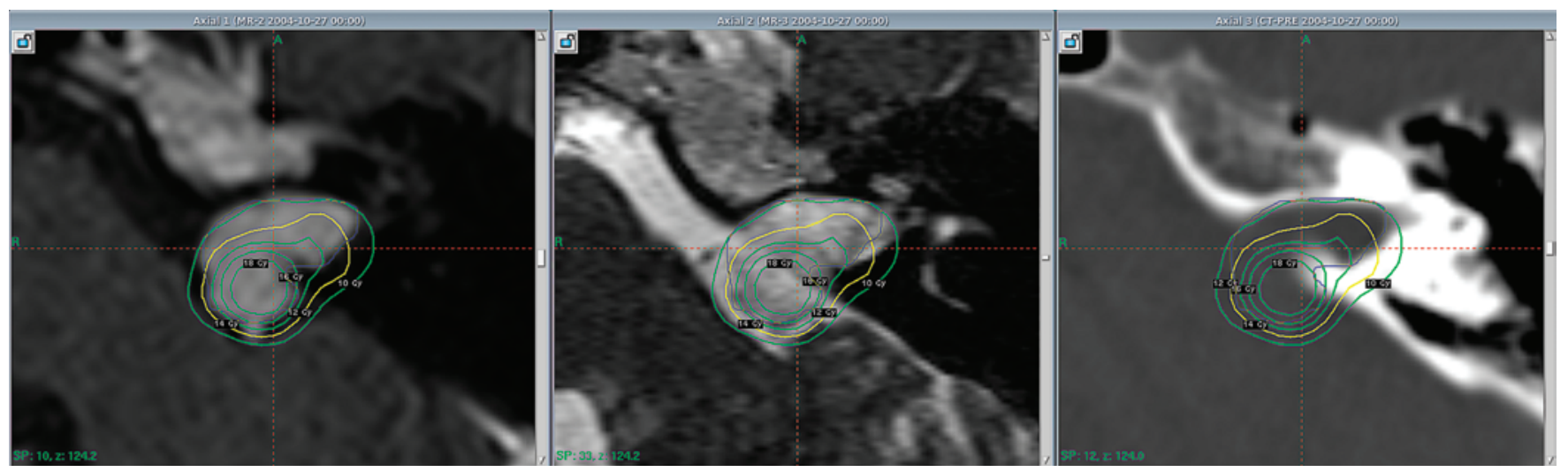

FIG. 1. Dose-planning technique using stereotactic MR images: a postgadolinium T1-weighted image (left), a 3D constructive interference in steady state image (center), and a CT scan (right). Yellow line, $12 \mathrm{~Gy}$; green lines, $18 \mathrm{~Gy}, 16 \mathrm{~Gy}, 14 \mathrm{~Gy}$, and $10 \mathrm{~Gy}$ from the center. To avoid excess irradiation to the facial and cochlear nerves, the anterior part of the tumor was not covered with a $12-G y$ isodose gradient.

Dose planning was performed using a Kula system (Elekta Instrument $\mathrm{AB}$ ) before 1995 and, thereafter, using a Leksell GammaPlan system (Elekta Instrument AB). In $93 \%$ of all cases, the target volume was covered with a $60 \%$ isodose gradient to obtain 12.0 Gy at the tumor periphery. Figure 1 shows our actual treatment plan, describing our SRS policy. To avoid excess irradiation to the facial and cochlear nerves, the anterior part of the tumor was covered with a 10.0-Gy isodose gradient in patients whose pre-SRS facial and/or cochlear functions were maintained. Therefore, $72 \%-99 \%$ of the entire tumor volume was irradiated with 12.0 Gy. Table 2 summarizes radiosurgical parameters, i.e., radiosurgical doses, coverage, Paddick conformity ${ }^{28}$ and gradient ${ }^{29}$ indices, and cochlear doses. Cochlear doses were determined based on CT scan results, with the bone window level set according to previously reported methods, $2,3,9,19,25,35$ i.e., mean and maximum doses. Cochlear doses were available in 67 of 74 patients with serviceable hearing but were not available in the other 7 due to the outdated computer system used in our earliest cases.

\section{Post-SRS Follow-Up}

Recommended follow-up includes these measures: 1) neurological examinations, particularly of fifth, seventh, eighth, and lower cranial nerve functions; 2) MR images, tumor size, enhancement changes, and ventricular size; and 3) PTA at 3-month intervals through the 18th post-SRS month, followed by 6-month intervals through the 36th post-SRS month and, thereafter, at 12-month intervals. MRI follow-up was performed at our facility in $100(55 \%)$ of the 183 patients. In these 100 patients, tumor volume was estimated at every examination using the Leksell GammaPlan system. All PTA was performed in the referring hospitals.

\section{Clinical Outcomes}

In patients who underwent follow-up MRI at our facility, volume was measured using the GammaPlan system. However, in patients who underwent follow-up MRI at other facilities, the same volume measurement technique could not be performed and only the maximum diameter (including the intracanalicular portion) was determined. Although 2 different measurements were used in this study, a $10 \%$ change in diameter was considered to be similar to a $25 \%$ volume change. Regarding tumor growth control, volume $\geq 125 \%$ or diameter $\geq 110 \%$ relative to the pretreatment volume or diameter was regarded as growth, volume $\leq 75 \%$ and/or diameter $\leq 90 \%$ was considered as shrinkage, and all other observations as no change.

In considerable numbers of patients, sequential MR images showed transient tumor expansion, which was regarded as tumor growth followed by shrinkage to the pre-SRS size or smaller within the 36th post-SRS month. ${ }^{27}$ Clinical tumor control was defined as there being no need for further procedures (FPs), i.e., salvage surgical removal or re-SRS. The FP-free survival time was defined as the interval between SRS and the day of salvage surgery or reSRS. An FP was judged to be necessary based not only on

TABLE 2. Summary of radiosurgical parameters for 183 patients

\begin{tabular}{cc}
\hline \multicolumn{1}{c}{ Parameter } & Value, Median (range) \\
\hline Radiosurgical doses, Gy & \\
\hline Min & $12.0(8.8-15.0)^{*}$ \\
\hline Mean† & $14.8(13.0-18.0)$ \\
\hline Max & $20.2(15.1-30.0)$ \\
\hline Coverage, \% & $92.0(72.0-99.0)$ \\
\hline Paddick conformity index & $0.72(0.14-0.88)$ \\
\hline Paddick gradient index & $3.30(2.61-5.09)$ \\
\hline Cochlear doses, Gy $\ddagger$ & \\
\hline Mean & $4.1(2.3-5.7)$ \\
\hline Max & $5.6(2.8-11.4)$ \\
\hline
\end{tabular}

\footnotetext{
* A minimum (margin) dose of 12.0 Gy was selected for 171 (93\%) patients. $\dagger$ Mean tumor doses were calculated for 170 patients. Doses could not be determined due to an outdated dose-planning system used for the earliest 13 patients.

$\ddagger$ Cochlear doses were calculated in patients with pre-SRS useful hearing. Doses could not be determined due to an outdated dose-planning system used for the earliest 7 patients.
} 
a tumor volume increase but also symptom progression. As to the end point, failures were regarded as events and any others as censored.

The PTA results were calculated using the following formula: PTA $=(a+2 b+c) / 4$, where $a, b$, and $c$ are threshold levels of $500 \mathrm{~Hz}, 1000 \mathrm{~Hz}$, and $2000 \mathrm{~Hz}$, respectively. According to the PTA classification of the Gardner-Robertson grading system, ${ }^{6}$ all patients were categorized into 3 groups: 1) $\leq 30 \mathrm{~dB}, 2)>30 \mathrm{~dB}$ and $\leq 50 \mathrm{~dB}$, and 3) $>$ $50 \mathrm{~dB}$. Serviceable hearing was defined as PTA $\leq 50 \mathrm{~dB}$. Hearing deterioration-free survival time was defined as the interval between SRS and the day on which a PTA decrease to $\leq 50 \mathrm{~dB}$ was documented. Regarding the end point, failures were regarded as events and any others as censored.

\section{Statistical Analysis}

All data were analyzed according to the intention-totreat principle. For baseline variables, summary statistics were constructed using frequencies and proportions for categorical data; and medians, means, and standard deviations for continuous variables.

For time-to-event outcomes, the cumulative incidences of FPs and hearing deterioration were estimated using the Kaplan-Meier method. ${ }^{17}$ Also, to identify baseline and clinical variables associated with FPs and hearing deterioration, univariable and multivariable analyses were performed with Cox proportional hazards regression models. For continuous variables, cutoff values were determined using receiver operating characteristic curves. Statistical analyses were performed using JMP 10.0 (SAS Institute). All comparisons were planned, and the tests were 2-sided. A $p$ value $<0.05$ was considered a statistically significant difference.

\section{Results}

\section{Tumor Control and FP-Free Interval}

The median MRI follow-up period was 114 months (interquartile range [IQR] 73-144 months). During this period, tumor shrinkage was documented in 110 (61\%) patients, no change in 48 (27\%), and growth in the other $22(12 \%)$. Therefore, the crude growth control rate was $88 \%$ in the present study. Actuarial tumor control rates were $93 \%, 87 \%$, and $82 \%$ at the 60th, 120th, and 180th post-SRS month, respectively. Among the 22 patients with tumor enlargement, 9 were carefully observed and have received no treatment thus far because no neurological deterioration has occurred. Salvage treatment was needed in the remaining 13. In addition to these 13 patients, 2 underwent salvage treatment due to rapid growth followed by shrinkage or facial palsy. As a result, an FP was required in $15(8 \%)$ patients, i.e., surgery in $9(5 \%)$, surgery followed by repeat SRS in $1(0.5 \%)$, and repeat SRS alone in $5(3 \%)$. Thus, the crude clinical tumor control rate was $92 \%$. Figure 2 shows the FP-free survival interval. Actuarial FPfree rates were $96 \%, 93 \%$, and $87 \%$ at the 60th, 120th, and 180th post-SRS month, respectively. Among the 100 patients who were followed in our facility (in whom tumor volume size was calculated at every follow-up visit), transient tumor expansion was observed in $50(50 \%)$.

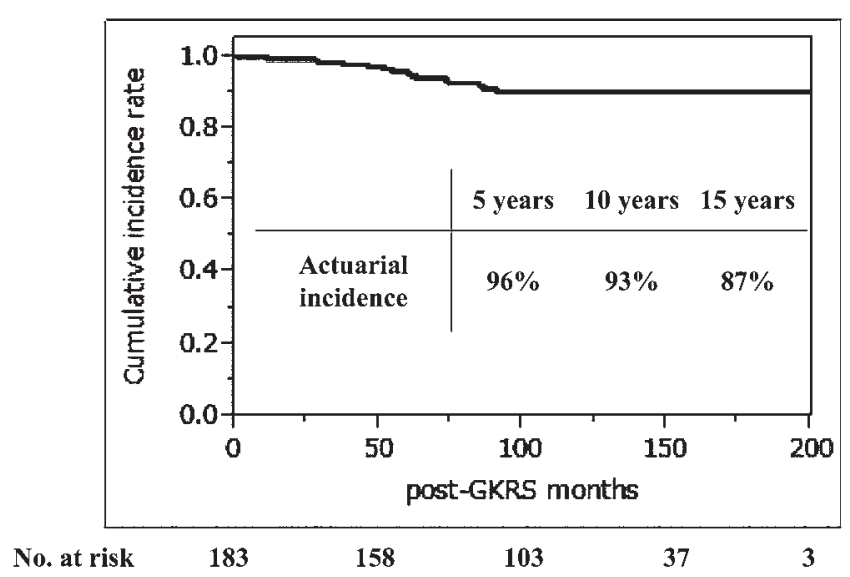

FIG. 2. Actuarial clinical control rates after SRS. GKRS = Gamma Knife radiosurgery.

Table 3 demonstrates pre-SRS factors possibly related to the necessity of an FP. Among various clinical factors, only cystic-type tumor (HR 3.36, 95\% CI 1.18-9.36; $\mathrm{p}=$ 0.02 ) was shown to be significantly unfavorable. Also, univariable analysis failed to show any correlation between the minimum dose and tumor control $(\geq 14 \mathrm{~Gy}$ vs $<14 \mathrm{~Gy}$ : HR 5.93, 95\% CI 0.93-21.5; $\mathrm{p}=0.06$ ).

\section{Post-SRS Functional Outcomes}

During the median clinical follow-up period of 114 months (IQR 73-144 months), trigeminal neuropathy occurred in $6(3 \%)$ patients: at the 6th post-SRS month in 2 and at the 9th, 16th, 36th, and 96th post-SRS month in 1 each. Trigeminal neuropathy occurrence was associated with a tumor volume increase in 2 patients. Two of the 6 patients have received meticulous follow-up observation because of mild symptoms, and the other 4 were administered carbamazepine. However, the trigeminal neuropathy was transient in 5 patients. Only 1 patient experienced prolonged trigeminal neuropathy.

Two patients experienced transient facial nerve palsy at 18 and 91 months after SRS. In the patient with earlier fa-

TABLE 3. Pretreatment clinical factors and radiosurgical parameters possibly related to clinical tumor control

\begin{tabular}{lccc}
\hline \multicolumn{1}{c}{ Variable } & HR & $95 \% \mathrm{Cl}$ & $\begin{array}{c}\mathrm{p} \\
\text { Value }\end{array}$ \\
\hline Age, $\geq 65$ vs $<65$ yrs & 0.78 & $0.22-2.29$ & 0.67 \\
\hline Pre-SRS growth, yes vs no & 1.07 & $0.33-2.02$ & 0.90 \\
\hline Prior removal, yes vs no & 2.06 & $0.72-5.74$ & 0.17 \\
\hline Tumor characteristic, cystic vs solid & 3.36 & $1.18-9.36$ & 0.02 \\
\hline Koos classification, Stage IV vs I-III & 2.51 & $0.78-7.07$ & 0.12 \\
\hline Tumor vol category, $\geq 8.0$ vs $<8.0 \mathrm{~cm}^{3}$ & 2.65 & $0.60-8.33$ & 0.17 \\
\hline Mean tumor dose, $\geq 14.3$ vs $<14.3$ Gy & 1.09 & $0.30-7.02$ & 0.91 \\
\hline $\begin{array}{c}\text { Paddick conformity index, } \geq 0.75 \text { vs } \\
<0.75 \text { Gy }\end{array}$ & 1.85 & $0.63-5.40$ & 0.25 \\
\hline Coverage, $<0.79$ vs $\geq 0.79$ & 2.70 & $0.15-13.46$ & 0.40 \\
\hline
\end{tabular}




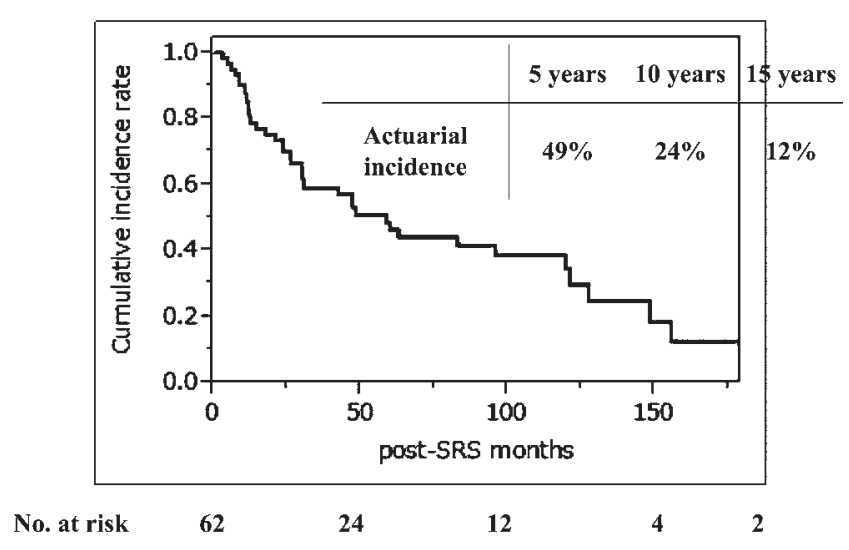

FIG. 3. Actuarial useful hearing preservation rates after SRS.

cial nerve palsy, the tumor volume increased from $0.9 \mathrm{~cm}^{3}$ at the time of SRS to $1.6 \mathrm{ml}$ at the 18th post-SRS month. Steroid treatment was continued for 90 days; thereafter, facial nerve functions normalized and have not deteriorated to date. The tumor gradually shrank to $0.27 \mathrm{~cm}^{3}$ at the 158th post-SRS month. In the patient with facial palsy at the 91st post-SRS month, the tumor volume had decreased from $0.68 \mathrm{~cm}^{3}$ at the time of SRS to $0.29 \mathrm{~cm}^{3}$ at the 84 th post-SRS month. At the 91st post-SRS month, the tumor volume was $0.61 \mathrm{~cm}^{3}$. This patient underwent a second SRS and received steroid therapy for 30 days. Thereafter, facial nerve functions normalized and have not deteriorated to date. The tumor gradually shrank to $0.23 \mathrm{~cm}^{3}$ at the 132nd post-SRS month. We retrospectively reviewed the dose planning for both of these patients. It was, however, impossible to determine whether the tumors had recurred from the portion irradiated with a lower dose. None of our patients experienced irradiation-related facial nerve disturbances.

Follow-up PTA was performed at a median post-SRS interval of 59 months (IQR 33-109 months). Among the 66 patients, serviceable hearing was maintained in 23 $(35 \%)$. Figure 3 shows hearing deterioration-free survival. Actuarial rates of hearing preservation were $49 \%, 24 \%$, and $12 \%$ at the 60 th, 120 th, and 180 th post-SRS month, respectively. Table 4 demonstrates pre-SRS clinical factors possibly related to hearing worsening. With multivariable analysis followed by univariable analysis, we found that more advanced age ( $\geq 65$ years: HR $2.66,95 \%$ CI 1.16 5.92; $\mathrm{p}=0.02)$, larger tumor volume $\left(\geq 8 \mathrm{~cm}^{3}\right.$ : HR 5.36, $95 \%$ CI $1.20-17.4 ; p=0.03$ ), and higher cochlear dose (mean cochlear dose > $4.2 \mathrm{~Gy}$; this cutoff value was calculated using the receiver operating characteristic curve based on our own data set: HR 2.22, 95\% CI 1.07-4.77; p $=0.03$ ) were unfavorable factors for hearing preservation. The actuarial survival curves for hearing preservation, divided according to these 3 significant factors, are shown in Fig. 4.

\section{Post-SRS Hydrocephalus}

Six patients had undergone ventriculoperitoneal shunt placement before SRS. After SRS, ventriculoperitoneal shunt placement for symptomatic hydrocephalus was required in 11 patients at a median post-SRS interval of 33 months (range 5 to 85 months).

\section{Discussion}

As detailed in the description of our dose-planning technique above, the tumor was not totally covered with a prescribed peripheral dose in most of our cases. The crude tumor growth and clinical control rates (88\% and 92\%, respectively) and actuarial FP-free fractions of 96\%, 93\%, and $87 \%$ at the 60 th, 120th, and 180th post-SRS month, respectively, were nonetheless considered to be favorable compared with previously reported results, ranging from $82 \%$ to $98 \%$, as listed in Table 5., $, 7,8,19,23,24,26$ Although various definitions of tumor growth were applied in prior studies, favorable tumor control rates did not differ widely among the previously reported results. Therefore, Gamma Knife SRS with the recently applied low-dose protocol, approximately $12 \mathrm{~Gy}$ at the tumor margin for small- to medium-sized VSs, is expected to achieve good long-term tumor control, similar to that reported with shorter-term follow-up results.

Our dose-planning technique, which avoids excess ir-

TABLE 4. Pretreatment clinical factors and radiosurgical parameters possibly related to hearing deterioration

\begin{tabular}{|c|c|c|c|c|c|c|}
\hline \multirow[b]{2}{*}{ Variable } & \multicolumn{3}{|c|}{ Univariable Analysis } & \multicolumn{3}{|c|}{ Multivariable Analysis } \\
\hline & $\mathrm{HR}$ & $95 \% \mathrm{Cl}$ & $p$ Value & $H R$ & $95 \% \mathrm{Cl}$ & $\mathrm{p}$ Value \\
\hline Age, $\geq 65$ vs $<65$ yrs & 3.42 & $1.61-6.99$ & 0.002 & 2.66 & $1.16-5.92$ & 0.02 \\
\hline Neurofibromatosis Type II & 1.45 & $0.23-4.92$ & 0.63 & & & \\
\hline Pre-SRS growth, yes vs no & 1.14 & $0.48-2.41$ & 0.75 & & & \\
\hline Hx of sudden deafness & 0.69 & $0.21-1.76$ & 0.47 & & & \\
\hline PTA level $>30$ vs $\leq 30 \mathrm{~dB}$ & 1.69 & $0.87-3.33$ & 0.11 & & & \\
\hline Prior removal, yes vs no & 1.36 & $0.32-3.82$ & 0.63 & & & \\
\hline Tumor characteristic, cystic vs solid & 1.18 & $0.56-2.32$ & 0.65 & & & \\
\hline Koos class, Stage IV vs I-III & 1.84 & $0.74-4.03$ & 0.18 & & & \\
\hline Tumor vol, $\geq 8.0$ vs $<8.0 \mathrm{~cm}^{3}$ & 4.75 & $1.10-14.45$ & 0.04 & 5.36 & $1.20-17.4$ & 0.03 \\
\hline Paddick gradient index, $\geq 3.21$ vs $<3.21$ & 0.56 & $0.29-1.11$ & 0.10 & & & \\
\hline Mean cochlear dose, $>4.2$ vs $\leq 4.2$ Gy & 2.54 & $1.28-5.23$ & 0.01 & 2.22 & $1.07-4.77$ & 0.03 \\
\hline
\end{tabular}


Age: $\geqq 65$ years vs $<65$ years

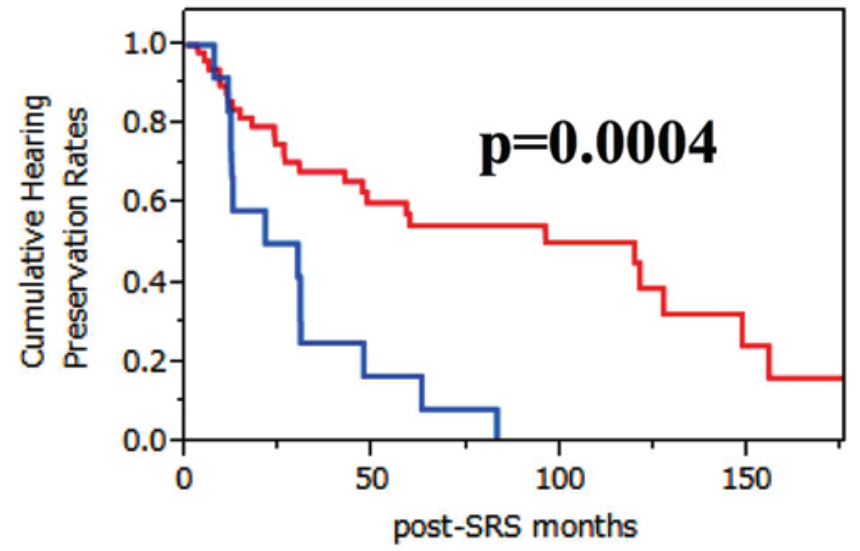

\section{Tumor Volume: $\geqq 8 \mathrm{~cm}^{3} \mathrm{vs}<8 \mathrm{~cm}^{3}$}

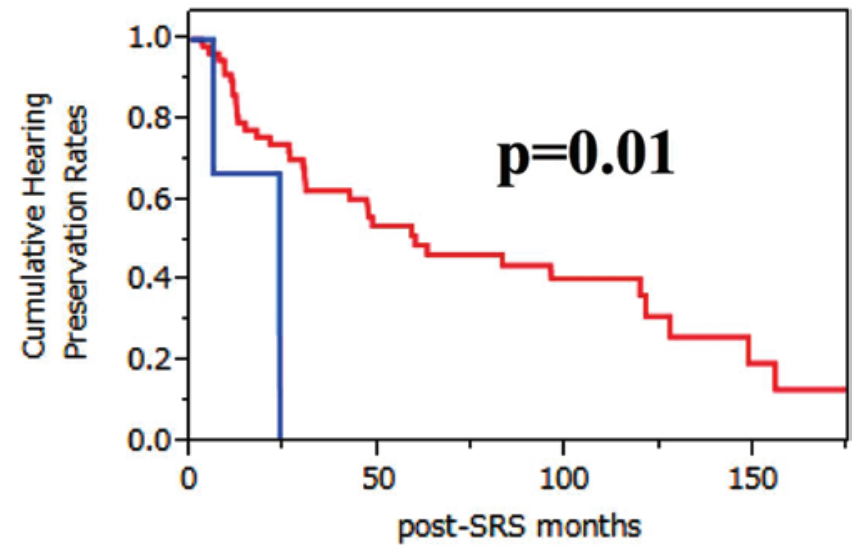

Cochlear dose: $>4.2$ Gy vs $\leqq 4.2$ Gy

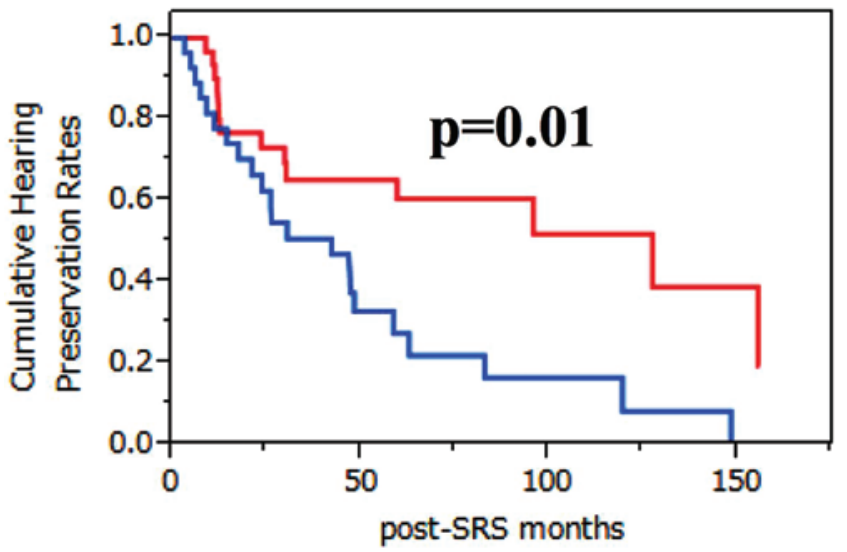

FIG. 4. Actuarial hearing preservation rates after SRS according to 3 significant clinical factors. There were significant differences between 2-sided data in age $(p=0.0004)$, tumor volume $(p=0.01)$, and cochlear dose $(p=0.01)$.

radiation to the facial and cochlear nerves, was shown to preserve facial nerve function; no patients experienced additional permanent deterioration of facial nerve function after SRS. However, regarding hearing preservation, our results - a crude preservation rate of $35 \%$ and cumulative rates of $49 \%, 24 \%$, and $12 \%$ at the 60th, 120th, and 180th post-SRS month, respectively-were not as favorable as we had hoped. As for hearing preservation, previous reports showed that the longer the follow-up period was, the lower the preservation rate tended to be. The longer follow-up periods might have resulted in lower hearing preservation rates in the time ranges examined; reported hearing preservation rates were $34 \%$ at the 8 th post-SRS year and $23 \%$ at the 10 th post-SRS year. ${ }^{4,8}$

As for clinical factors contributing to loss of serviceable hearing, there were statistically significant correlations between hearing deterioration and more advanced age, larger tumor volume, and higher cochlear dose. Although there are a few reports on fractionated stereotactic radiation therapy of VSs, ${ }^{1,20}$ these studies did not have sufficiently long posttreatment observation periods. We must carefully monitor further long-term treatment results to determine whether our protocol achieves better outcomes than those of single-session SRS.

Notably, we obtained no evidence that tumor progression occurred at the anterior part of an intracranial tumor, i.e., the lower coverage area. Rather, in all cases with tumor progression, the cisternal portion enlarged in all directions, i.e., medial, posterior, anterior, upward, and/or downward. Thus, it was difficult to determine the part(s) that had actually enlarged.

\section{Tumor Control and Larger Tumor Volume}

Among various pre-SRS clinical factors and radiosurgical parameters, a larger tumor volume is generally recognized as being significantly unfavorable for tumor growth control, as shown by both our present results and previous reports. ${ }^{4,5,8,10,19,23,24,26,32}$ However, 2 groups, Liu et al. ${ }^{23}$ and Milligan et al., ${ }^{26}$ reported good long-term tumor control rates (82\%-97\%) after SRS for relatively large VSs, i.e., mean tumor volumes were $10.8 \mathrm{~cm}^{3}$ in the former and 9.4 $\mathrm{cm}^{3}$ in the latter study.

\section{Hearing Outcomes and Cochlear Dose}

Reported hearing preservation rates after SRS varied markedly (from 28\% to 79\%) in long-term follow-up studies. ${ }^{4,8,23,24,27,34}$ According to most previous reports, a larger tumor volume including Koos stage and an older patient age were shown to be unfavorable predictive factors for hearing preservation. ${ }^{5,9,33,36}$ However, Yang et al..$^{36}$ performed a systematic review of SRS for VS and concluded that large tumors and older patient ages do not appear to be associated with any increased risk for hearing loss after SRS compared with younger patients and/or those with smaller tumors. Although Franzin et al. ${ }^{5}$ and Hasegawa et al. ${ }^{9}$ reported that the only positive predictive factor for hearing preservation was having GardnerRobertson Class I hearing prior to treatment, hearing preservation rates in our study did not differ significantly between patients in Gardner-Robertson Classes I and II. Franzin et al. ${ }^{5}$ reported that patients with presenting symptoms other than hearing loss have better hearing outcomes. Further studies are needed to clarify the impacts of these factors.

In addition to the aforementioned factors, cochlear dose was recently recognized as likely to be related to a de- 
TABLE 5. Summary of published reports of postradiosurgical long-term follow-up for VSs

\begin{tabular}{lcccccc}
\hline \multicolumn{1}{c}{ Authors \& Year } & No. of Pts & Tumor Vol, $\mathrm{cm}^{3}$ & FU, Mos & Tumor Control, \% & Freedom of FP, \% & Rate of Hearing Preservation, \% \\
\hline Kondziolka et al., 2004 & 157 & - & Median 109.2 & 98 & 98 & 47 \\
\hline Lunsford et al., 2005 & 252 & Mean 2.5 & $\geq 10$ yrs in 252 pts & - & 97 (10 yrs) & $79(6 \mathrm{yrs})$ \\
\hline Liu et al., 2006 & 74 & Mean 10.8 & Median 68 & 96 & 97 & 79 \\
\hline Carlson et al., 2013 & 44 & Mean 1.7 & Median 112 & 97 & 97 & $23(10 \mathrm{yrs})$ \\
\hline Milligan et al., 2012 & 22 & Median 9.4 & Median 66 & $82(5 \mathrm{yrs})$ & 82 & $28(5 \mathrm{yrs})$ \\
\hline Hasegawa et al., 2013 & 440 & Median 2.8 & Median 150 & 92 & 92 & 34 (8 yrs) \\
\hline Present study, 2016 & 183 & Median 2.0 & Median 114 & 88 & 92 & 35 \\
\hline
\end{tabular}

$\mathrm{FU}=$ follow-up; pts = patients; $-=$ no data.

crease in hearing acuity after SRS. . $3,3,1,16,21,22,25,33-35$ Several in vivo studies have examined radiation effects on the cochlea, as previously reported. Hulcrantz et al. stated that in a pregnant mouse model, scanning electron microscopy revealed that both inner and outer hair cells were missing in large numbers of exposed animals, irrespective of the irradiation dose, and that remaining hair cells, as well as pillar cells, showed signs of degeneration. ${ }^{13}$ Furthermore, a dose-dependent, time-related damage pattern was demonstrated in the cochlea, with pathological changes affecting both outer and inner hair cells. ${ }^{12}$ These studies support the idea that hair cells are the most vulnerable structures in the cochlea. Thus, radiation-induced damage to the cochlea might account for the difference in hearing decrease between the 2 sides. Therefore, lowering of cochlear doses has been discussed in relation to better hearing preservation rates after SRS. The cutoff points applied in our study, which were mainly between 3 Gy and 4 Gy, are presented in Table 6.

\section{Comparison of Hearing Preservation With Natural Hearing Decrease}

Our crude hearing preservation rate was $35 \%$, and the actuarial useful hearing preservation rates were $49 \%, 24 \%$, and $12 \%$ at the 5 th, $10 \mathrm{th}$, and 15 th post-SRS year, respectively. These outcomes are clearly not satisfactory. However, according to previous reports describing long-term outcomes, the longer the follow-up period was, the lower the hearing preservation rate tended to be. When considering the clinical significance of these results, it is important to compare hearing preservation with the course of untreated natural hearing decreases. Previous reports have shown that hearing tends to decrease even in untreated cases. Régis et al. reported that the wait-and-see policy exposes the patient to elevated risks of tumor growth and hearing deterioration, with the probability of long-term functional hearing preservation being very poor $\left(40 \%\right.$ at 4 years). ${ }^{31}$ Hajioff et al. stated that hearing deteriorated substantially even in patients whose tumors did not grow, but did so faster when tumors grew significantly?

\section{Weaknesses of the Current Study}

The major weakness of this study might be that a retrospective cohort was used and, therefore, the clinical factors are obviously heterogeneous. However, we believe that these heterogeneous patient groups rather closely reflect actual clinical practice. In fact, as physicians, we often encounter inhomogeneous clinical factors. The more homogeneous a patient group is, the more scientific the study becomes. However, the results obtained are applicable only to a select patient group, making them ever farther from actual clinical practice.

Another possible weakness of this study might be that the only audiometric follow-up method was PTA, i.e., speech discrimination scores (SDS) were not obtained. Thus, our results for hearing preservation may have been overestimated. In fact, patient hearing functions should be estimated using both PTA and SDS. Jacob et al..$^{15}$ reported that SDS correlated significantly with time to nonserviceable hearing. We are now collecting SDS after SRS for VS. One Japanese study has already shown a correlation between PTA and SDS in patients with VS. Based on results for 607 ears, Kimitsuki et al..$^{18}$ demonstrated that all patients with VS who had PTA $\leq 50 \mathrm{~dB}$ maintained $\geq 50 \%$ of hearing acuity according to SDS. Thus, PTA $\leq 50 \mathrm{~dB}$ in VS cases might be regarded as correlating with $\geq 50 \%$ hearing acuity according to SDS.

\section{Conclusions}

Stereotactic radiosurgery achieved good long-term results in our series. Tumor control was acceptable, and there were few serious complications in patients with small- to medium-sized VSs. Unfortunately, hearing preservation

\section{TABLE 6. Published reports on cochlear doses}

\begin{tabular}{ll}
\multicolumn{1}{c}{$\begin{array}{c}\text { Authors } \\
\text { \& Year }\end{array}$} & \multicolumn{1}{c}{$\begin{array}{c}\text { Cochlear Factors Affecting } \\
\text { Hearing Outcomes }\end{array}$} \\
\hline Linskey et al., 2003 & Intratemporal inner ear \\
\hline Massager et al., 2007 & Mean cochlear dose \\
\hline Lasak et al., 2008 & Mean cochlear dose $\geq 4.75$ Gy \\
\hline Timmer et al., 2009 & Max cochlear dose \\
\hline Tamura et al., 2009 & Modiolus 4.0 Gy \\
\hline Kano et al., 2009 & Mean cochlear dose >4.2 Gy \\
\hline Wackym et al., 2010 & Max cochlear dose \\
\hline Hasegawa et al., 2011 & Mean cochlear dose \\
\hline Brown et al., 2011 & Mean \% vol of cochlea $>5.3$ Gy \\
\hline Baschnagel et al., 2013 & Mean cochlear dose 3.0 Gy, \% vol $\geq 3.0$ Gy \\
\hline Present study, 2016 & Mean cochlear dose $>4.2$ Gy \\
\hline
\end{tabular}


was not satisfactory. However, the longer the observation period is, the more important it becomes to compare postSRS hearing decreases with the natural decline in hearing acuity in untreated cases.

\section{Acknowledgments}

We thank Bierta E. Barfod, Katsuta Hospital Mito GammaHouse, for her help with language editing of this manuscript.

\section{References}

1. Aoyama H, Onodera S, Takeichi N, Onimaru R, Terasaka $\mathrm{S}$, Sawamura Y, et al: Symptomatic outcomes in relation to tumor expansion after fractionated stereotactic radiation therapy for vestibular schwannomas: single-institutional long-term experience. Int J Radiat Oncol Biol Phys 85:329-334, 2013

2. Baschnagel AM, Chen PY, Bojrab D, Pieper D, Kartush J, Didyuk O, et al: Hearing preservation in patients with vestibular schwannoma treated with Gamma Knife surgery. J Neurosurg 118:571-578, 2013

3. Brown M, Ruckenstein M, Bigelow D, Judy K, Wilson V, Alonso-Basanta M, et al: Predictors of hearing loss after gamma knife radiosurgery for vestibular schwannomas: age, cochlear dose, and tumor coverage. Neurosurgery 69:605614, 2011

4. Carlson ML, Jacob JT, Pollock BE, Neff BA, Tombers NM, Driscoll CL, et al: Long-term hearing outcomes following stereotactic radiosurgery for vestibular schwannoma: patterns of hearing loss and variables influencing audiometric decline. J Neurosurg 118:579-587, 2013

5. Franzin A, Spatola G, Serra C, Picozzi P, Medone M, Milani $D$, et al: Evaluation of hearing function after Gamma Knife surgery of vestibular schwannomas. Neurosurg Focus 27(6):E3, 2009

6. Gardner G, Robertson JH: Hearing preservation in unilateral acoustic neuroma surgery. Ann Otol Rhinol Laryngol 97:55-66, 1988

7. Hajioff D, Raut VV, Walsh RM, Bath AP, Bance ML, Guha A, et al: Conservative management of vestibular schwannomas: third review of a 10 -year prospective study. Clin Otolaryngol 33:255-259, 2008

8. Hasegawa T, Kida Y, Kato T, Iizuka H, Kuramitsu S, Yamamoto T: Long-term safety and efficacy of stereotactic radiosurgery for vestibular schwannomas: evaluation of 440 patients more than 10 years after treatment with Gamma Knife surgery. J Neurosurg 118:557-565, 2013

9. Hasegawa T, Kida Y, Kato T, Iizuka H, Yamamoto T: Factors associated with hearing preservation after Gamma Knife surgery for vestibular schwannomas in patients who retain serviceable hearing. J Neurosurg 115:1078-1086, 2011

10. Hasegawa T, Kida Y, Kobayashi T, Yoshimoto M, Mori Y, Yoshida J: Long-term outcomes in patients with vestibular schwannomas treated using Gamma Knife surgery: 10-year follow up. J Neurosurg 102:10-16, 2005

11. House JW, Brackmann DE: Facial nerve grading system. Otolaryngol Head Neck Surg 93:146-147, 1985

12. Hultcrantz M: Correlation between auditory brainstem recordings and morphology as seen through the scanning electron microscope. Scanning Microsc 2:1725-1737, 1988

13. Hultcrantz M, Anniko M, Borg E: The influence of prenatal gamma irradiation on the ageing of the cochlea. Acta Otolaryngol 108:414-423, 1989

14. International RadioSurgery Association: Stereotactic Radiosurgery for Patients with Vestibular Schwannomas. Radiosurgery Practice Guideline Report \#4-06. Harrisburg, PA: International RadioSurgery Association,
2006 (http://www.irsa.org/AN\%20Guideline.pdf\#search= 'Stereotactic+Radiosurgery+for+Patients+with+Vestibular+ Schwannomas.+Radiosurgery+Practice+Guideline+Report') [Accessed July 7, 2016]

15. Jacob JT, Carlson ML, Schiefer TK, Pollock BE, Driscoll CL, Link MJ: Significance of cochlear dose in the radiosurgical treatment of vestibular schwannoma: controversies and unanswered questions. Neurosurgery 74:466-474, 2014

16. Kano H, Kondziolka D, Khan A, Flickinger JC, Lunsford LD: Predictors of hearing preservation after stereotactic radiosurgery for acoustic neuroma. J Neurosurg 111:863873, 2009

17. Kaplan EL, Meier P: Nonparametric estimation from incomplete observations. J Am Stat Assoc 53:457-481, 1958

18. Kimitsuki T, Matsumoto N, Shibata S, Tamae A, Ohashi M, Noguchi A, et al: [Correlation between the maximum on speech discrimination score and pure-tone threshold.] Audiology Japan 57:158-163, 2011 (Jpn)

19. Kondziolka D, Lunsford LD, Flickinger JC: Acoustic neuroma radiosurgery. Origins, contemporary use and future expectations. Neurochirurgie 50:427-435, 2004

20. Kranzinger M, Zehentmayr F, Fastner G, Oberascher G, Merz F, Nairz O, et al: Hypofractionated stereotactic radiotherapy of acoustic neuroma: volume changes and hearing results after 89-month median follow-up. Strahlenther Onkol 190:798-805, 2014

21. Lasak JM, Klish D, Kryzer TC, Hearn C, Gorecki JP, Rine GP: Gamma Knife radiosurgery for vestibular schwannoma: early hearing outcomes and evaluation of the cochlear dose. Otol Neurotol 29:1179-1186, 2008

22. Linskey ME, Johnstone PA, O'Leary M, Goetsch S: Radiation exposure of normal temporal bone structures during stereotactically guided Gamma Knife surgery for vestibular schwannomas. J Neurosurg 98:800-806, 2003

23. Liu D, Xu D, Zhang Z, Zhang Y, Zheng L: Long-term outcomes after Gamma Knife surgery for vestibular schwannomas: a 10-year experience. J Neurosurg 105 Suppl:149-153, 2006

24. Lunsford LD, Niranjan A, Flickinger JC, Maitz A, Kondziolka D: Radiosurgery of vestibular schwannomas: summary of experience in 829 cases. J Neurosurg $\mathbf{1 0 2}$ Suppl:195-199, 2005

25. Massager N, Nissim O, Delbrouck C, Delpierre I, Devriendt $\mathrm{D}$, Desmedt $\mathrm{F}$, et al: Irradiation of cochlear structures during vestibular schwannoma radiosurgery and associated hearing outcome. J Neurosurg 107:733-739, 2007

26. Milligan BD, Pollock BE, Foote RL, Link MJ: Long-term tumor control and cranial nerve outcomes following $\gamma$ knife surgery for larger-volume vestibular schwannomas. J Neurosurg 116:598-604, 2012

27. Nagano O, Higuchi Y, Serizawa T, Ono J, Matsuda S, Yamakami I, et al: Transient expansion of vestibular schwannoma following stereotactic radiosurgery. J Neurosurg 109:811-816, 2008

28. Paddick I: A simple scoring ratio to index the conformity of radiosurgical treatment plans. Technical note. J Neurosurg 93 (Suppl 3):219-222, 2000

29. Paddick I, Lippitz B: A simple dose gradient measurement tool to complement the conformity index. J Neurosurg 105 Suppl:194-201, 2006

30. Pollock BE, Driscoll CL, Foote RL, Link MJ, Gorman DA, Bauch CD, et al: Patient outcomes after vestibular schwannoma management: a prospective comparison of microsurgical resection and stereotactic radiosurgery. Neurosurgery 59:77-85, 2006

31. Régis J, Carron R, Park MC, Soumare O, Delsanti C, Thomassin JM, et al: Wait-and-see strategy compared 
with proactive Gamma Knife surgery in patients with intracanalicular vestibular schwannomas. J Neurosurg 113 Suppl:105-111, 2010

32. Sun S, Liu A: Long-term follow-up studies of Gamma Knife surgery with a low margin dose for vestibular schwannoma. J Neurosurg 117 Suppl:57-62, 2012

33. Tamura M, Carron R, Yomo S, Arkha Y, Muraciolle X, Porcheron D, et al: Hearing preservation after Gamma Knife radiosurgery for vestibular schwannomas presenting with high-level hearing. Neurosurgery 64:289-296, 2009

34. Timmer FC, Hanssens PE, van Haren AE, Mulder JJ, Cremers CW, Beynon AJ, et al: Gamma Knife radiosurgery for vestibular schwannomas: results of hearing preservation in relation to the cochlear radiation dose. Laryngoscope 119:1076-1081, 2009

35. Wackym PA, Runge-Samuelson CL, Nash JJ, Poetker DM, Albano K, Bovi J, et al: Gamma Knife surgery of vestibular schwannomas: volumetric dosimetry correlations to hearing loss suggest stria vascularis devascularization as the mechanism of early hearing loss. Otol Neurotol 31:14801487, 2010

36. Yang I, Sughrue ME, Han SJ, Aranda D, Pitts LH, Cheung SW, et al: A comprehensive analysis of hearing preservation after radiosurgery for vestibular schwannoma. J Neurosurg 112:851-859, 2010

\section{Disclosures}

The authors report no conflict of interest concerning the materials or methods used in this study or the findings specified in this paper.

\section{Author Contributions}

Conception and design: M Yamamoto, Watanabe, Kawabe. Acquisition of data: M Yamamoto, Kawabe, Koiso. Analysis and interpretation of data: M Yamamoto, Watanabe. Drafting the article: Watanabe. Critically revising the article: M Yamamoto, Watanabe, T Yamamoto. Reviewed submitted version of manuscript: all authors. Approved the final version of the manuscript on behalf of all authors: M Yamamoto. Statistical analysis: Watanabe. Administrative/technical/material support: M Yamamoto. Study supervision: M Yamamoto, T Yamamoto, Matsumura, Kasuya.

\section{Correspondence}

Masaaki Yamamoto, Katsuta Hospital Mito GammaHouse, 5125-2 Nakane, Hitachi-naka, Ibaraki 312-0011, Japan. email: bcd06275@nifty.com. 